\title{
Extent and pattern of leverage use in community mental healthcare: an exploratory study from the UK Kathleen Sheehan* and Tom Burns
}

Address: University of Oxford, Department of Psychiatry, Warneford Hospital, Oxford, OX3 7JX, UK

* Corresponding author

from WPA Thematic Conference. Coercive Treatment in Psychiatry: A Comprehensive Review

Dresden, Germany. 6-8 June 2007

Published: 19 December 2007

BMC Psychiatry 2007, 7(SuppI I):S69 doi:10.1 I86/I47I-244X-7-SI-S69

This abstract is available from: http://www.biomedcentral.com/I47I-244X/7/SI/S69

(c) 2007 Sheehan and Burns; licensee BioMed Central Ltd.

\section{Background}

As psychiatric treatment shifts from the hospital to the community, policy debates have increasingly focused on the use of legal compulsion to mandate treatment in the community. In service provision, however, it is apparent that legal compulsion is just one form of leverage used to engage patients in community treatment. Research from the USA indicates that approximately half of communitybased patients have experienced some form of leverage. The aim of this study was to explore the extent to which leverage is used in the UK and to investigate whether leverage is applied differentially to patients receiving treatment from various mental health service teams.

\section{Methods}

Structured interviews were conducted with patients receiving treatment from community mental health and substance misuse teams in Oxford, UK. The interview schedule was an adapted version of that used by Monahan et al. [1] in the USA and investigated the use of criminal sanction, welfare benefits, housing and child custody as leverage.

\section{Results}

Preliminary data characterizing the sample populations and describing the pattern of leverage experienced by community mental health and substance misuse patients will be presented. Associations between leverage, perceived coercion and sociodemographic and clinical characteristics will also be examined.

\section{Conclusion}

This small study provides a basis for further investigation of the use of leverage in community mental healthcare in the UK. An understanding of when and how leverage is used to engage patients in psychiatric care is of importance for both mental health policy and practice.

\section{References}

I. Monahan J, Redlich AD, Swanson J, Robbins PC, Appelbaum PS, Petrila J, Steadman HJ, Swartz M, Angell B, McNiel DE: Use of leverage to improve adherence to psychiatric treatment in the community. Psychiatr Serv 2005, 56:37-44. 